\title{
The Reasons for the Declining Reputation of Comedy films -take Mahua Funage as an Example
}

\author{
Chunxia Huang ${ }^{1, \dagger}$, Junlong Tao ${ }^{2, *}, \dagger$, Juyi Wang ${ }^{3, \dagger}$ \\ ${ }^{1}$ School of political science and law, Shaoguan University, 200000, Shanghai, China 1 \\ ${ }^{2}$ Business School, The Chinese University of Hong Kong, 999077, Hong Kong, China 2 \\ ${ }^{3}$ School of Economics and Management, Shanghai Maritime University, 201306, Shanghai, China 3 \\ *Corresponding author.Email:1155124550@link.cuhk.edu.hk \\ These authors contributed equally.
}

\begin{abstract}
This study built on the in-depth analysis of Mahua Funage's declining film reputation in the film market. In recent years, the decline of film reputation in the China movie market has gradually become a serious problem that cannot be ignored. We used python crawler to collect about 800 online review comments from Maoyan about the 4 movies of Mahua Funage to do the sentiment analysis, keyword analysis, and comparative analysis. Our findings indicated that audiences expressed a positive attitude to Mahua Funage's early works but negative to Mahua Funage's recent films. What's more, the keyword and contrast analysis suggested that Mahua Funage had some problems in actors, theme, creation, propaganda, and other aspects, and these problems may be important reasons for the decline of reputation. We presented four suggestions on actors and performances, appropriate themes, original creative story teams, and sincere-hearted publicity based on the analysis. This paper can help Mahua Funage find out why the declining word of mouth and work as a meaningful reference to the whole film market.
\end{abstract}

Keywords: Script, Humour, Funny, Punchline.

\section{INTRODUCTION}

With the development of the economy, cultural consumption in China had increased. Movies had become an important part of people's entertainment life in China. In 2021, the Chinese Spring Festival film market set several records with a box office of 78.23 billion yuan and 159 million moviegoers [1]. Until now, the box office of Chinese mainland films is becoming the secondlargest ticket warehouse worldwide [2]. It indicated that the movie industry had a rapid development in China. There are many promising movie companies in China, such as Mahua Funage, a China comedy movie company that has had rapid growth in recent years. However, while attendance and ticket sales have exploded, word of mouth had declined [3]. The release of many films and the entry of a large amount of capital had spawned many bad films. To some extent, the increasing commercialization process has led to a decline in the quality and reputation of films. To analyze the reasons for the decline of film reputation in recent years, we took Mahua Funage as the research object and conducted a series of analyses.
Existing research has explored the business model of Mahua Funage [4], publicity strategy meaning of culture [5], and the development in the 5G era. [6] Through this research, we can learn that Mahua Funage has its own unique business model and promotes its business growth through multi-channel communication and benefits. What's more, Mahua Funage kept pace with the times to promote its own development, which was of great significance to cultural undertakings. However, in recent years, the ratings of Mahua Funage films on major movie platforms such as Maoyan, Douban have been declining, and word of mouth has fallen badly. Even though some entertainment media's criticism and analysis of Mahua Funage's recent works online [7], there was still a lack of systematic research on the causes of the recent decline of Mahua Funage's work. To some extent, it is important to explore the reasons for Mahua Funage's declining reputation. As a representative company in China's film industry, Mahua Funage can reflect the problem of declining word of mouth in the whole industry in China, even though it is a different all over the world.

This paper aims to find the common solutions to the problem of the falling word-of-mouth for the companies 
like Mahua Funage. Based on online review comments, this paper mainly used text mining and sentiment analysis. We found that the problems mainly exist in four aspects: acting, actors, content, and propaganda. In terms of these questions, we gave a variety of suggestions. Our contribution is as follows: we have found the main reasons why the reputation of Mahua Funage's films is declining nowadays and then give other similar companies significant reference to help them to be prosperous in the future.

\section{METHODOLOGY}

\subsection{Mahua Funage}

Mahua Funage, a China comedy company that began with stages plays, rapidly developed the movie industry in recent years. In terms of the nature of the company Mahua Funage is owned by Chinese and local companies, and it is not on the list in the stock market. It proves that Mahua Fuange is a typically local Chinese entertainment company with no foreign investment. It provides great help for us to study the word of mouth of the Chinese drama movie market.

\subsection{Data Collection}

To analyze the word of mouth of Mahua Funage's movie, the online review comments of the audience who had watched the movie are crucial and useful for the whole research. The online review comments are one of the important factors in the box office and word of mouth. [8] In China, the most popular and timeliness movie comment platform is Maoyan (https://maoyan.com/). We decided to choose 4 typical movies from Mahua Funage called "Goodbye Mr. Loser", "Never say die", "Li Cha's aunt", "Hotel never set" (the first two are the reputable representatives and the last two are the representatives of disrepute). Based on these movies, we used the python crawler to request the server of this platform so that we can get the first 200 online review comments per film based on the heat of the comment and there were 800 reviews in total.

\subsection{Research Process}

In the first stage, we cleaned our data by deleting a variety of useless and meaningless words such as actors' names, memes, emotionless objects, and some inevitable errors made by the procedure. In the second stage, we used people's emotions to access the quantization and embodiment of people's emotions and their true psychological statements when watching the movies. In the third stage, we used text mining analysis. We utilized the user comments to process word frequency statistics and then refined the keywords, enabling us to further research. Compared to the sentiment analysis, it represented more comprehensively to reflect the tendency of people's thoughts, whether positive or negative. In the fourth stage, we utilized comparative analysis as a comprehensive summation. By comparing the sentiment analysis tables of four movies: two positives and the other two negatives, we can see totally different opinions. As a result, we could find a general law of consensus in both positive and negative films by deeply observing the words enumerated in the tables and can conclude people's preferences and aversion. Pitching in a small area then analyzing in a strategic and broadway is our objective. In the fifth stage, the reflection of the existing problems and potential advantages could strongly support us to think about overall strategies for them to overcome the difficulties and catch up with the tendency of our era. It may not be mentioned or focused on in other articles before to be a step of strong significance.

\section{RESULT AND DISCUSSION}

\subsection{Basic Description of the Data}

We used "Goodbye Mr. Loser" and "Never Say Die" as the representative two films with a good reputation and used "Li Cha's aunt" and "Hotel never set" as the representative two films with poor reputation.

\subsection{Sentiment Analysis Results}

We presented the research data in 2 tables, which reflected the sentiment analysis for the 4 movies. The first movie and second movie called "Goodbye Mr. Loser", "Never say die" are the early work of Mahua Funage and the rest two movies called Li Cha's aunt", "Hotel never set" are the recent work of Mahua Funage.

Tablel shows the sentiment result about the movie "Goodbye Mr. Loser" and "Never say die". It indicated that the customers overall have a more good viewing evaluation of this movie. For example, for the positive term of the comment of "Goodbye Mr. Loser", the most count terms are "laugh", "love," and "good," which have counts of 49, 17, and 13. These partly reflected the audience's appreciation of the film. In contrast, this movie still had some negative comments but based on the table, and the negative terms appeared much less often than positive terms. The "Never say die" also has a greater number of positive terms than negative terms. Generally, the reputation of the early movie work of Mahua Funage was good, and the audience's sentiment towards these two movies was generally positive. 
Table 1. The sentiment of Goodbye Mr. Loser and Never say die

\begin{tabular}{ccccc}
\hline & \multicolumn{2}{l}{ Goodbye Mr. Loser } & \multicolumn{2}{c}{ Never say die } \\
\hline & Content & Count & Content & Count \\
\hline Positive & laugh & 49 & smile & 73 \\
& love & 17 & good & 16 \\
& good & 13 & joke & 7 \\
nice & 10 & surprised & 4 \\
& moving & 8 & moving & 4 \\
excellent & 4 & well & 4 \\
negative & nausea & 11 & not good & 6 \\
& vulgar & 4 & boring & 5 \\
bad & 3 & bad & 3 \\
& no & 3 & mediocre & 3 \\
terrible & 3 & no & 2 \\
ridiculous & 2 & cheap & 2 \\
& & &
\end{tabular}

Table 2. The sentiment of Li Cha's aunt and Hotel never set

\begin{tabular}{|c|c|c|c|c|}
\hline & \multicolumn{2}{|c|}{ Li Cha's aunt } & \multicolumn{2}{|c|}{ Hotel never set } \\
\hline & Content & Count & Content & Count \\
\hline \multirow[t]{4}{*}{ Positive } & laugh & 52 & laugh & 13 \\
\hline & nice & 7 & interesting & 6 \\
\hline & laughter & 7 & warmth & 5 \\
\hline & easy & 6 & good & 5 \\
\hline \multirow[t]{8}{*}{ Negative } & nausea & 16 & rotten & 20 \\
\hline & bad & 15 & bad & 18 \\
\hline & vulgar & 12 & ugly & 10 \\
\hline & $\begin{array}{c}\text { disappoi } \\
\text { nted }\end{array}$ & 12 & terrible & 9 \\
\hline & boring & 11 & rubbish & 9 \\
\hline & ugly & 7 & $\begin{array}{c}\text { incomprehe } \\
\text { nsible }\end{array}$ & 8 \\
\hline & worst & 6 & boring & 6 \\
\hline & unwell & 6 & waste & 6 \\
\hline
\end{tabular}

Table 2 showed different features from Table 1 . Although the count of the positive terms had a main percentage in the whole data, there was a significant increase of the negative terms for these two movies. Specifically, it revealed that the number of the term with two digits count had increased significantly. For example, the typical negative terms of "Li Cha's aunt" is "nausea", "bad," and "vulgar," which have counts of 16, 15, 12. It indicated that it's possible that the audience had very negative feelings about the film in terms of the actors and performances. As for "Hotel never set", there had also been a significant increase in negative terms associated with the film. Based on the data, we chose the typical negative terms, which were "rotten", "ugly," and "waste," which had the counts $20,10,6$. Based on the basic analysis, we could know that the customer may have some negative sentiment to the public way or the plot content of Mahua Funage. Generally, the reputation of the recent work of Mahua Funage has decreased, and the customers' sentiment towards these two movies is generally negative.

Above all, the reputation of Mahua Funage's recent films has been in a significant decline compared to its earlier works. As for the details of the difference, we needed further analysis to study it and seek reasonable solutions.

\subsection{Text mining Results}

3.3.1. "Hotel Never Set" (3.6) (3.6 is the score on Maoyan, the followings are the same)

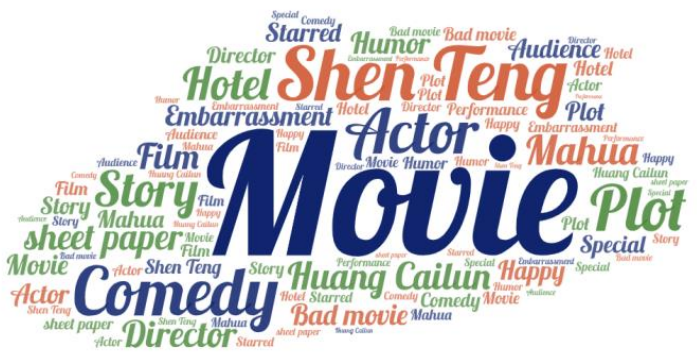

Figure 1 The word clouds of Hotel never set

Table 3. The keywords of Hotel never set

\begin{tabular}{cccc}
\hline & \multicolumn{3}{l}{ Hotel Never Set } \\
\hline Content & Count & Content & Count \\
Huang Cailun & 25 & happy & 17 \\
scrip & 25 & humor & 16 \\
actors & 22 & special & 15 \\
stories & 22 & film & 15 \\
director & 19 & performance & 14 \\
embarrassment & 19 & starred in & 13 \\
bad & 18 & Zhang Huiwen & 13 \\
plot & 18 & express & 12 \\
hotel & 17 & feeling & 11 \\
audience & 17 & appealing & 11 \\
\hline
\end{tabular}


The top keywords contained in "Li Cha's aunt" was "Huang Cailun", "Scrip", "Actors", "Stories" and "Embarrassment", which respectively count 25, 25, 22, 22 , and 19. We found the problems existed in three aspects through deeper excavating the words. Firstly, the embarrassing act triggered the audience's dissatisfaction, and people were dissatisfied with the main actors' theatrical performance. Secondly, after putting them into the specific comments, we found that this film was suspected of false propaganda. Before the movie's release, Mahua Funage's team promoted Shen Teng, the famous actor of Mahua Funage as a friendship actor. However, when the customer came to the cinema, they found that they were deceived. Shen Teng only appeared on the KT board and did not play any role in the drama. Deceptive propaganda was also one of the factors that lead to the audience's hatred. Thirdly, we gathered the original comments centered on "Story". People felt bored with the content and confused with the internal logic. The unclear topic positioning made the film deviate from its inherent advantages and characteristics.

\subsection{2. "Li cha's aunt" (7.9)}

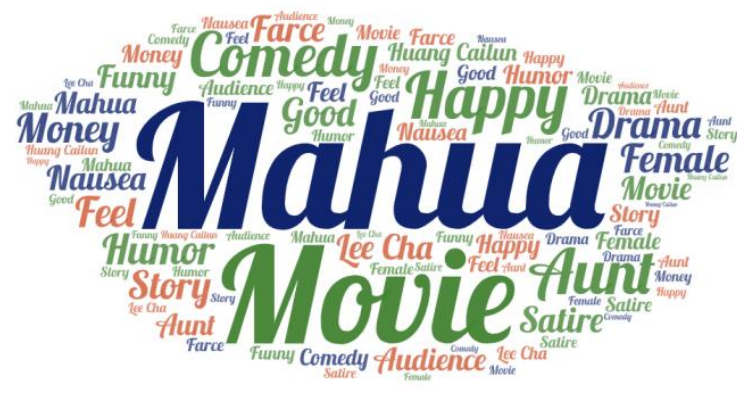

Figure 2. The word clouds of Li Cha's aunt

Table 4. The keywords of Li Cha's aunt

\begin{tabular}{cccc}
\hline \multicolumn{4}{c}{ Li Cha's aunt } \\
\hline Content & Count & Content & Count \\
punchline & 25 & bad & 15 \\
audience & 23 & satire & 15 \\
Money-oriented & 23 & farce & 14 \\
female & 21 & feel & 14 \\
stories & 18 & disguise & 14 \\
Huang Cailun & 17 & awkward & 13 \\
lee cha & 16 & The richest & 13 \\
nausea & 16 & Lu Jingshan & 13 \\
funny & 16 & plot & 12 \\
like & 16 & vulgar & 12 \\
\hline
\end{tabular}

The representative words in "Li Cha's aunt" were "punchline" (25), "Money-oriented" (23), "Female" (21), "Stories" (18), and "Huang Cailun" (17). We found the complete sentences of the comments according to these keywords, which indicated the main problems were concentrated on their project and the content. Although a punch audience was fascinated by their punchlines, the tendency of vulgarization was disliked by most audiences. Explicit plots and incorrect value conveyed were something belied their strength of lighthearted humor and led to obvious detest among the audience. For example, the whole film conveyed the value of money worship and materialism, the main tone of the movie was based on the get-rich-quick foundation rather than some positive power. What's more, we learned that the audience is disgusted by the cross-dressing appearance of Huang Cailun, the star of "Li Cha's Aunt, so the unsuitable appearance of the actors was also one of the factors.

\subsection{3. "Goodbye Mr. Loser" (9.3)}

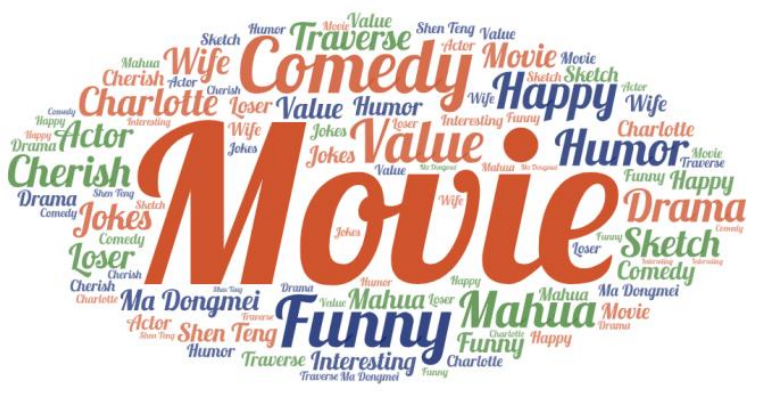

Figure 3.The word clouds of Goodbye Mr. Loser

Table 5.The keywords of Goodbye Mr. Loser

\begin{tabular}{cccc}
\hline \multicolumn{3}{c}{ Goodbye Mr. Loser } \\
\hline Content & Count & Content & Count \\
funny & 33 & interesting & 16 \\
happy & 30 & sketch & 15 \\
value & 28 & jokes & 14 \\
like & 24 & wife & 14 \\
punchline & 23 & Shen Teng & 14 \\
Ma Dongmei & 21 & loser & 14 \\
charlotte & 19 & actor & 13 \\
cherish & 19 & life & 13 \\
traverse & 17 & plot & 13 \\
drama & 16 & good & 13
\end{tabular}

We could see the words with high frequency in this film was "Funny" (33)", "Happy" (30), "Value" (28), "Like" (24), "Punchline" (23), and so on. We emphasized 
that the original sentences contained these words and found most of the comments towards it were positive. People appreciated it strongly and regarded it as a milestone in comedy. The good performance of the audience eliminated the feeling of embarrassment, which always exists in the other two films. Superb acting, the cast of powerful actors, a theme with positive energy, and some unique originality can be four main prompts for its success of word-of-mouth. Ma Li and Shen Teng, the representative actors, gave a superb performance during the transition from high school to adulthood in the film. Through a vivid act of real feeling, they helped the audience recall their youth and pure love, rich in both laughter and tears. When talking about the originality of this product, just like the actors' line frequently mentioned by the viewers "Ma Dongmei", it was still talking with relish in people's mouth to describe the situation of quickly forgotten, become a meme everyone knows. Although a few people confused it with daydreams, most people highly commended it.

\subsection{4. "Never Say Die” (9.1)}

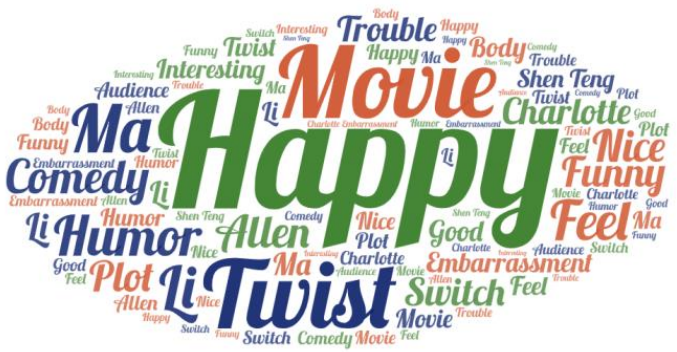

Figure 4. The word clouds of Never say die

Table 6. The keywords of Never say die

\begin{tabular}{cccc}
\hline \multicolumn{4}{c}{ Never Say Die } \\
\hline Content & Count & Content & Count \\
happy & 56 & trouble & 20 \\
humor & 39 & Shen Teng & 20 \\
embarrassment & 33 & nice & 18 \\
Charlotte & 28 & plot & 17 \\
funny & 27 & body & 16 \\
Ma Li & 25 & audience & 16 \\
interesting & 25 & good & 16 \\
Allen & 24 & plot & 15 \\
feel & 21 & stories & 15 \\
switch & 20 & like & 14
\end{tabular}

The words that existed on top were "Happy" (56), "Humor" (39), and "Embarrassment" (33), which indicated a hybrid comment towards this film.
Fortunately, most of the comments were positive. After excavating the comment sentences, we found that most people were split their sides with laughter. We can infer that the content and project of the film were appealing to the audience. Similar to "Goodbye Mr. Loser", it contained superb acting, a cast of powerful actors, a theme with positive energy, and some unique originality. The difference between them was that it added more laughs accompanied by some incomprehension with the punchline.

\section{COMPARATIVE ANALYSIS}

\subsection{The Cast and Acting Force}

Like the examples we mentioned above, the representative actors and actresses like Shen Teng, Mali, and Ai Lun were the protagonists in "Goodbye Mr. Loser" and "Never Say Die", bringing a strong brand effect to attract the audience. The celebrities of Mahua Funage could be a powerfully positive implication of good quality for the audience. Conversely, just like the two films with a poor reputation, "Li Cha's aunt" and "Hotel never set", the main actors and actresses were Huang Cailun, Zhang Huiwen, Lu Jinshan, and so on. They seemed anonymous and noteless contrasted to Shen Teng and Mali who were widely known. Big-name actors can be a key factor for the box office and word-of-mouth because people got used to accepting someone they are familiar with.

What's more, the smooth and natural acting was also vastly important, which mainly depended on the actors' dramatic speaking and acting skills. The acting of celebrities like Shen Teng and $\mathrm{Ma} \mathrm{Li}$ was widely appreciated. In contrast, the acting in the other two films was disguised because of the mechanical appliance and exaggerated performance.

In conclusion, the choice of suitable actors and vivid acting can be a watershed event for whether a film will be reputable.

\subsection{Suitable Materials and Project}

As soon as we searched for the label of the two reputable films, we could clearly find their labels were full of positive energy. The commonality of "Goodbye Mr. Loser" and "Never Say Die" were focused on the warm-blooded and uncompromising spirit, which could easily relate to people's hearts. Teen comedy films are popular contemporarily, so the films with this project can easily grab the audience's attention. The films with a poor reputation like "Li Cha's aunt" and "Hotel never set" not only did not strengthen their original characteristics but also introduced new elements the audience didn't like. People always relate the films of Mahua Funage to the new year, so they are for an all-age audience and convey the idea of family happiness. The vulgarization and 
money worship showed in the films obviously deviate from the theory.

\subsection{Content Creation}

Based on the previous analysis, we could know that the two reputable films had good original content, bringing happiness to the customer. However, the two movies called "Li Cha's aunt "and "Hotel never set" frequently broke out with bad jokes and low-level jokes. Specifically, in terms of contrast, it was the big difference of content creation between the early works and recent works of Mahua Funage. There were many original comedy contents for the first two movies, such as "Ma Dongmei" and "Yi Jian Mei". These contents brought joy to the audience and led the direction of comedy for a long time and reflected the strong creative ability of Mahua Funage. For the recent two movies, the old jokes and lowlevel jokes frequently appeared in the movies such as "cross-dressing style" and "Little people chase after rich girls". The creation method of Mahua Funage not only made the audience feel disgusted and boring but also made people think that the movies of Mahua Funage were suspected of plagiarism. The bottom line was that Mahua Funage's creativity is on the wane.

\subsection{Propaganda Way}

Based on the sentiment analysis and keyword analysis, we can conclude that in the movie "Hotel never set," Mahua Funage said that Shen Teng would appear in this movie with friends so that Mahua Funage can attract more audiences to watch the movie. However, Shen Teng only appeared on the KT board. In terms of contrast, it was about the problem of the publicity and the sincerity of the whole company. For the early works of Mahua Funage, the company used the best actors and a series of online and offline campaigns to attract audiences to the film. It made the audiences feel sincere and contributed to the success of Mahua Funage's early works. However, it was irresponsible for the audience to attract the audience through semi-false propaganda for the recent two works. In a word, Mahua Funage was not as sincere as before, and its respect for the audience was not as good as before.

\section{STRATEGY AND DISCUSSION}

Through the contrast analysis between the films with rave reviews and unwelcome films, we found the defect in the current strategies of Mahua Funage.

\subsection{The Right Actors and Apt Performance}

When talking about the cast and acting, they should learn from their mistakes, choosing the widely acclaimed actors who could represent their enterprise image rather than someone was often questioned. The actors with whom the audience is familiar could be positive propaganda for introducing a new film, a solid foundation for a good reputation. Therefore, famous actors and actresses like Shen Teng and Mali should be intensively cultivated to promote the growth of Mahua Funage's films. In addition, they should emphasize the acting in the films, which could bring an intensive sense of identification for the audience and therefore get the support of more people. They should put more money and time into the detailed and specialized acting to make the scenario more eye-catching.

\subsection{Suitable Materials and Projects}

When discussing suitable materials and projects, the failure of their recent films could be a strong illustration of the decisive influence of proper content. The content positioning of Mahua Funage was to the audience with all range of age. The positive and youthful project could be immortal and highly regarded by the audience, so there was no need for them to give up their existing advantage and pursuit some new elements which aren't fit in their characteristic. They should excavate the deeper value of the project like youth and pure love, which they are good at making rather than some vulgar content they are unfamiliar with. In conclusion, they should play their own game instead of following the fashion blindly.

\subsection{The Creation of a Creative Team}

When talking about content creation, the decreasing of the creative content of Mahua Funage's movie works essentially indicated that the creative ability of Mahua Funage was decreasing badly. If this company wanted to improve its creative ability, it was very important to focus on its creative team. A good creative team was the foundation of a good original film with a reputation. The declining quality of mahua Funage's original content also suggested that the creative ability of mahua Funage's original team is declining. To solve this, Mahua Funage should extend its creative team by employing more young and excellent writers to have more creative ideas and follow the Times. What's more, the company should also organize the creative team to learn more good comedy work worldwide so that they could learn great experience from other comedians. Only the films produced by the good creative team could have a good reputation.

\subsection{Sincere Propaganda}

When talking about the propaganda way Mahua Funage's semi-false publicity made, the customer feels that this company lack sincerity. If Mahua Funage wanted to recover the reputation, it was necessary to use a sincere way of publicity to save the customer's disappointment. One possible way was that Mahua Funage should stop making false publicity and focus more on creating the trailers so that it could really attract more audiences. 
What's more, holding more sincere online and offline activities to the customer was also important. The company should hold activities such as offline fans meetings or online interactive activities on Weibo or the official platform with fans. The customer could get more benefits from these activities to show more sincerity to them and recover the reputation.

\section{CONCLUSION}

Based on the analysis of the case Mahua Funage, we summarized the main reasons why their word-of-mouth has been continuously declined and then extended them into the whole industry. Through a series of analysis on the data of online review comments in Maoyan, we found the main factors lead to their recent failure was their actors, performance, content, and value conveyed. Moreover, authenticity can also be a decisive part which they discarded now. After summarizing the reasons, we provided a variety of objective and detailed suggestions for the Mahua Funage. As for the significance of our indepth analysis introduced the vicissitude of the Mahua Funage's films through an easy-to-digest process, which enabled the viewers to appreciate the complete picture of the whole industry represented by the Mahua Funage through a small pointcut. Our findings were especially useful to the film companies focus on the same field as Mahua Funage. They can benefit from the function of reference and get the base for their future strategies, so it provided great significance for them. The topic we chose had profound meaning for the comedy industries, even closely relevant to their future development.

\section{REFERENCES}

[1] Hou, Guangming, See the vitality and potential of Chinese film market from the Spring Festival in 2021, Chinese Film Market, no.6, 2021, pp. 12-19.

[2] Dai, Debao, and Jibin Chen. Research on Mathematical Model of Box Office Forecast through BP Neural Network and Big Data Technology. Journal of Physics: Conference Series, vol. 1952, no. 4, 2021, pp. 042118., DOI: http://dx.doi.org/10.1088/17426596/1952/4/042118.

[3] Wang, Tao, and Wang, Qianwei, Paradox and Breakthrough: On the "High Opening and Low Going" of Domestic Films, Movie Literature, no. 8, 2021, pp. 102-105.

[4] Wang, Manqing, Research on the Business Model of Happy Twist- Analysis Based on the Business Model Canvas Mode, Trade Fair Economy, no.14, 2021, pp. 36-38. DOI: http://dx.doi.org/10.12245/j.issn.2096-

6776.2021.14.12
[5] Chen, Liangdong, Bring forth the New: The Cultural Form and creative Power of Chinese comedy Films in the 21st century, Movie Review, vol.4, 2021, pp.13-19,

DOI: http://dx.doi.org/10.3969/j.issn.10026916.2021.04.004

[6] Luo, Xiaoyu, Research on brand Marketing Innovation strategy of "Mahua Funage" comedy in 5G Era, News Dissemination, no.2, 2021, pp. 69-71

[7] Zhao, Mengdi, Li, Danzhou, The scenery and hidden worries of Chinese comedy film creation -- Taking Mahua Funage as an example, Culture Industries, no. 21,2020 , pp. $72-74$

[8] Lei, Gang, Lui, Lu, Zhou, Changhui, Empirical Analysis on the Impact of Online Film Rating on Box Office, Film Art, no.3, 2019, pp. 146-153 